\title{
A New Solution for Automatic Microstructures Analysis from Images Based on a Backpropagation Artificial Neural Network
}

\author{
Victor Hugo C. de Albuquerque ${ }^{1 *}$, Paulo C. Cortez ${ }^{2}$, Auzuir R. de Alexandria ${ }^{3}$, \\ João Manuel R. S. Tavares ${ }^{1}$.
}

\footnotetext{
${ }^{1}$ Instituto de Engenharia Mecânica e Gestão Industrial (INEGI), Faculdade de Engenharia da Universidade do Porto (FEUP), Departamento de Mecânica e Gestão Industrial (DEMEGI), Rua Dr. Roberto Frias, S/N, 4200 - 465 Porto - Portugal.
}

${ }^{2}$ Universidade Federal do Ceará (UFC), Departamento de Engenharia de Teleinformática, Av. Mister Hull, S/N - Pici, CEP 60455-970, Fortaleza - Ceará, Brasil.

${ }^{3}$ Centro Federal de Educação Tecnológica do Ceará, Indústria, NSMAT, Av. Treze de Maio, 2081 Benfica , CEP 60040-531, Fortaleza - Ceará, Brasil. 


\begin{abstract}
This paper presents a new solution to segment and quantify the microstructures from images of nodular, gray and malleable cast irons, based on an Artificial Neural Network. The neural network topology used is the multilayer perception, and the algorithm chosen for its training was the backpropagation. This solution was applied to 60 samples of cast iron images and results were very similar to the ones obtained by visual human tests. This was better than the information obtained from a commercial system that is very popular in this area. In fact, this solution segmented the images of microstructures materials more efficiently. Thus, we can conclude that it is a valid and adequate option for researchers, engineers, specialists and professionals from materials science field to realize a microstructure analysis from images faster and automatically.
\end{abstract}

Key words: Artificial neural networks; Image processing and analysis; Image segmentation and quantification; Microstructures; Multilayer perception; Materials Science.

\title{
1. Introduction
}

One of the most challenges in the machines and equipments development is the conception of systems with intelligent capacities, so then they could behave like humans. Important advances have been happening in the Artificial Intelligence area, and its biggest objective is the research of new algorithms and technological solutions that can be used in the development of new systems with stronger intelligent capacities. However, this is a very challenging and complex task, because there are a lot of actions that people commonly and naturally do as, for example, visualizing, hearing, walking and talking that are very hard to implement in computational systems.

Between all of those actions, vision has deserved special attention of the research community because of the considerable number of existing applications and its great importance in our society [1]. Primarily derived from Artificial Intelligence field, Computational Vision became a distinct research 
area and its objective is to construct systems and hardware solutions that can be able to perform some visual information analysis and interpretation, which can help humans in the execution of some usual and important tasks with higher speed and precision [2]. This new area uses, between others, techniques from Artificial Intelligence, Digital Signal Processing and Pattern Recognition [3].

Artificial neural networks are commonly used in Artificial Intelligence, Pattern Recognition and in Material Science fields. Particularly, they have been used in applications that involve objects recognition from images with high parallelism degree, considerable speed classification and important capacity to learn from examples [4].

In this work is presented a new solution to quantify the metallic materials microstructures from images based on a neural network. To test our solution, we used several images samples of nodular, malleable and gray cast irons. These materials have been selected because they are commonly used by industries, as in, for example, structures of machines, lamination cylinders, main bodies of valves and pumps and gear elements. Additionally, we compared the results obtained using our solution with the ones resulted using a commercial system widely used in Materials Science area for the same purpose.

This paper is organized in the following sections. In section two, the materials and artificial neural networks are introduced. Afterwards, the computational solution developed is described. Then, in section four, some experimental results and their discussion are presented. Finally, the main conclusions are addressed in the paper's last section.

\section{Materials and Artificial neural networks}

The main goal of this work was the development of a new solution to segment and quantify automatically the constituents of nodular malleable and gray cast irons from images. The solution developed and the cast irons consideration, are briefly explained into the following sections. 


\subsection{Cast Irons}

Cast irons are mainly composed by iron and carbon, being the percentage of the last one between 2.14 and 6.70\%. In fact, the most cast irons contain between 3.0 and $4.5 \%$ of carbon [17]. Beside carbon, the cast irons present significant silicon contents and, therefore, some authors as, for example, Callister [17], Chiaverini [18] and Raabe et al. [19], consider the cast iron as an iron alloy, with carbon and silicon. Another cast irons characteristic is associated to the carbon's appearance. In gray cast irons, all the carbon is presented practically free with the appearance of lamellar graphite or in veins, while in the white cast iron the carbon presented is arranged in the form of cementite $\left(\mathrm{Fe}_{3} \mathrm{C}\right)$ [20].

In accordance with the carbon content, cast irons can be classified as hypoeutectic, eutectics or hypereutectic. When eutectic cast iron is solidified, there is the formation of a microstructure with cementite and austenite globules, called ledeburite I. Continuing the cooling process, below $727^{\circ} \mathrm{C}$, the austenite transforms itself into pearlite globules on the cementite, forming ledeburite II [21], which deserved main attention of our work.

\subsection{Artificial Neural Networks}

Artificial neural networks can be applied to solve many engineering problems like function approximation and classification as in cases that exist nonlinear relations between the dependent and independent variables.

Nowadays, artificial neural networks are being used in Material Sciences for welding control [25]. It can obtain the relations between process parameters and correlations in Charpy impact tests [26], model alloy elements [27, 28], microstructures, mechanical steels properties [30] and the deformation mechanism of titanium alloy in hot forming [31]; predict weld parameters in pipeline 
welding, properties of austempered ductile iron, the carbon contents and the grain size of carbon steels [29]; build models to predict the flow stress and microstructures evolution of a hydrogenised titanium alloy [34].

Many systems of image processing and analysis have been developed using artificial neural networks. This is possible because of their main characteristics, like robustness to the presence of noisy data inside the input images, speed execution and their possibility to be parallel implemented. Zhang presents a review that is about the usage of neural networks on several image processing and analysis tasks [37].

The neural network paradigm is to construct a composed model using considerable number of neurons, being each one a very simple processing unit, with a great number of connections between them. The information among the neurons in the network is transmitted through the synaptic weights. Artificial neural networks flexibility and its capacity to learn and to generalize the information are very attractive and important aspects to justify their choice to solve many complex problems. In fact, the generalization associated to the network capacity of learning from a training set of examples and their ability to supply correct results to input data that was not presented in the training set, demonstrates that this neural network capacity goes further than the easy establishment of relations between inputs and outputs. This way, artificial neural networks are capable to extract information not presented in explicit forms in the training examples considered [35].

Different topologies and algorithms for neural networks can be found. In this work, it was used a neural network multilayer perception, which is a feed forward neural network type [36]. Usually, a multilayer perception network is composed of several layers lined up with neurons. Then, the input data is presented into its first layer and is distributed trough the internal hidden layers. The last neural network layer is the output one, where the problem's solution can be obtained. The input and output layers can be separated by one or more hidden layers, also called intermediate layers. In many applications of neural networks just one hidden layer is considered. Beyond this, the neurons of a layer 
are connected to the immediately neurons, so there are not unidirectional communication or connection among the neurons of the same layer. All neural layers are totally connected.

For the training of the multilayer perception network, we adopted a backpropagation algorithm, which is the most used for this neural network structure.

\section{Solution Developed}

The computational solution developed had as its main objective the microstructures segmentation and quantification presented in metallographic and microphotography images, using a neural network multilayer perception. For this purpose, each pixel of the input images is classified according to the microstructures element (pearlite, cemetite, graphite, martensite.). In the same way for the neural network inputs are considered the R, G and B color components of each images pixel; each microstructure element is classified corresponding to an individual output of the neural network. Pseudo colors are used to represent each microstructure segmented in the output images.

More specifically, the artificial neural network used is composed by 39 neurons distributed in two layers. The neurons distribution along the network layers (topology) corresponds to: 3 inputs, 30 neurons inside the hidden layer and 9 neurons in the output layer. As a consequence, it is expected that nine microstructure types come to be segmented

For the neural network training, it is necessary to consider some microstructures pixels in a representative metallographic image. This selection is done manually using the mouse device over that training image. The training algorithm used is the standard backpropagation [16]. For each type of material to be analyzed, it is necessary to perform the network training. 
After this, the network can analyze each pixel of an input image, and then perform the microstructures’ segmentation. During this phase, each pixel of the input image is classified and counters are used to quantify the microstructures identified.

Our solution was implemented using $\mathrm{C}++$ and the environment Builder 6 from Borland in Microsoft Windows XP platform. This new system was tested considering several image samples of cast irons. Some of the results obtained are presented and discussed in the next section.

\section{Experimental Results and Discussion}

To make an experimental test in our new computational system we used several samples of nodular, malleable and gray cast irons. Additionally, to validate the results obtained, a commercial system commonly used in Materials Science field for the same purpose was also considered. Moreover, in metallographic images, the nodular cast iron has the morphological graphite well defined and the quantification method manual was also considered [22]. In all images considered in this experiment the graphite is associated to the black color, while the pearlite or ferrite are to the gray color.

In Table 1, are shown the results obtained from images of a nodular cast iron using our solution and the commercial system considered. With this, we can notice that the results obtained using the two systems are very similar, presenting a minimum difference of $2.15 \%$ and a maximum of $7.1 \%$, for

samples 14 and 9, respectively. In addition, it is clear that our solution presents an average of graphite equal to $12.09 \%$ and of pearlite or ferrite to $87.91 \%$ and that the commercial system presents $15.93 \%$ and $84.07 \%$, respectively, being the difference between them of 3.84\%.

Figures 1a), b) and c), present an original image of a nodular cast iron, and the resultant images from the accomplished segmentation process using the commercial system and ours, respectively. These images are the ones that present the greatest difference between the results obtained by the two systems. On the other hand, images 1d), e) and f), are the ones that present the minor difference. 
In face of this, we noticed that the segmentation done using our solution is more accurate than the one obtained using the commercial system because it erroneously segmented and classified as graphite part of the pearlite or ferrite, what not occurred with our solution. This fact is the most important reason for the presented divergence in the results obtained by the two systems.

In Table 2, are presented the average results obtained using the manual quantification and the both computational systems, and it can be easily distinguished from the ones that are obtained by these systems. This occurs because the manual quantification tends to be an extremely tedious and fastidious procedure, and consequently, propitious to generate errors. Furthermore, to do the manual quantification with less than 5\% of error, it was necessary to analyze 206 points of each material sample, using for that, a reticulated mesh with 25 intersections [23]. The average results obtained using the manual quantification was $24.13 \%$ for graphite and $75.87 \%$ for ferrite or pearlite.

For the gray cast iron it was not possible to do the manual quantification because the graphite appears in the image samples like ribbings (lodes). However, the two computational systems considered can adequately segment and quantify the constituent of this type of iron as well.

In Table 3, are presented the results of the quantification using the two computational systems on gray cast iron images. Considering all materials analyzed, these are the most similar results obtained by the two systems because they present a minimum difference of $0.1 \%$ and a maximum of $6.44 \%$, for samples 1 and 11, respectively. Moreover, we can notice that our solution presents an average of graphite equal to $10.28 \%$ and of pearlite or ferrite to $89.62 \%$, and on the other hand, the commercial system presented $12.09 \%$ and $87.91 \%$, respectively, being the difference between them equal to $1.71 \%$.

Figures 2 a), b) and c), presents the original image of the gray cast iron used, and the resultant images of the segmentation done using the commercial system and ours, respectively. These images are the ones that present the minor difference between all the results. By contrast, images of Figures $2 \mathrm{~d}$ ), e) and f), are the ones that present the biggest difference. 
Analyzing the results obtained considering the gray cast iron, it can be concluded that the segmentations done using the two systems are very similar for sample 1 . Relatively to sample 11 , the segmentation carried through by visual inspection was very similar to the ones obtained using the computational systems; however, the quantification obtained by these systems presents a difference of $6.44 \%$.

The results obtained using the two systems on samples of nodular and gray cast iron are very similar, as the associated images have good quality and the material constituents are well defined and with very distinct gray levels.

If the two computational systems are applied on images of malleable cast irons with good quality, the results obtained are also very similar, as the graphite presents the same tonality that has in other irons, being just different in its morphology that, in this case, has an appearance similar to flakes. Thus, it was decided to apply our solution and the commercial system in images of malleable cast iron of low quality in which the ash levels of graphite are very similar to the one of pearlite or ferrite. This permitted the evaluation of the efficiency and efficacy of the two systems when they are used in more adverse conditions.

In Table 4, are presented the quantification results obtained by using our solution and the commercial system considered on a malleable cast iron. These results are the most different for the studied materials, presenting a minimal difference of $3.55 \%$ and a maximum of $15.16 \%$ for samples 18 and 4, respectively. Moreover, we noticed that our system presents a medium number of graphite equal to $14.98 \%$ and of pearlite or ferrite to $85.02 \%$ and the commercial system presents $22.89 \%$ and $77.11 \%$, respectively, being the difference between them of $7.91 \%$.

Figures $3 \mathrm{a}$ ), b) and c), present an original image of the malleable cast iron and the images resultant from the segmentation done using the commercial system and ours, respectively. These images present the minor difference verified between the two systems. On the other hand, the images of Figures $3 \mathrm{~d}$ ), e) and f), present the major difference. 
Verifying the results, we can notice that the segmentations obtained using the two systems are considerable distinct from each other on sample 4. The same happens with sample 18 because the commercial system segments great part of the pearlite or ferrite because of the low quality of the original input image. However, this error was not verified when our solution was tested because it segmented correctly the graphite from the other constituents.

From the results obtained by the commercial system considering samples of nodular, gray and, in particular, malleable casting iron (that its commonly used in Materials Science area), we can verify its difficulty to segment adequately the graphite when the background of the input image was not uniform. However, our system does not present that difficulty and so it is able to get results effectively even when used in more severe conditions.

The proposed solution shows to be a versatile and easy tool to use in automatic segmentation and quantification of material microstructures from images, even when the analyzed images are of low quality. Additionally, when compared to the commercial system elected in this work for comparison and validation purposes, our system showed that needs less time for the quantification of the structures presented in the input images.

\subsection{Application on Others Microstructures}

Our computational system can also be used successfully in the microstructures analysis of others metallic materials from images. For example, in Figure 4a), an original microphotography of an AISI 1020 steel is showed, the black color represents the pearlite grain and the white color, the ferrite. The segmentation obtained using our system is shown in Figure 4b) and the green color corresponds to pearlite grain and yellow color to ferrite. As we can verify in these images, our system segmented adequately the pearlite and ferrite. 
In Figure 5a), an original microphotography of an AISI 1045 steel is showed. The black color represents the pearlite grain and the white color, the ferrite grain. After the segmentation done using our system we obtained the image presented in Figure 5b), in which the red color corresponds to pearlite grain and the black color to ferrite. As we can see, the proposed solution segmented adequately this image sample.

Another possible important application of our computational system can be found in the segmentation and quantification of metallic materials inclusions [24]. Two examples of the results obtained by our system in this particular application are presented in Figure 6.

\section{Conclusions}

This paper described a new computational solution, based on an artificial neural network, that was applied to segment and quantify the constituents of metallic materials from images.

After the several experimental tests done, considering different metal samples, we can concluded that the system developed can be successfully used in the Materials Science area to do the segmentation and quantification of material microstructures from images. All those experiments showed some advantages about using our system. The most important ones were the simple and easy way that it can be used and the less sensitive to noise presented in the input images, mainly, due to optic distortions or irregular illumination originated by the image acquisition process.

Additionally, in this work we compared and validated the results obtained by our system with the corresponding ones obtained using one commercial system very common in the Materials Science area. From this comparison we could conclude that our system was easier to use, better when there was complex applications conditions, and that its results always had better quality and could be obtained faster. 
Finally, we can conclude that our computational system is suitable to be used by researchers, engineers, specialists and others professionals from the Materials Science area, as an adequate option to optimize the segmentation and quantification of microstructures of materials from images, obtaining accurate and fast results.

\section{Acknowledgments}

To Federal Center of Technological Education of Ceará - CEFET CE, in particular to Mechanical Testing Laboratory, and to Tele-Information Laboratory for the support given during the accomplishment of this work. The authors would like to thank also to CAPES for their financial support.

\section{References}

[1] F. P. C. Souza, A. Susin, SIAV - An automatic vehicle identification system, XIII Brazilian Conference on Automática (2000), 1377-1380.

[2] B. Acha, C. Serrano, Image classification based on color and texture analysis, IWISPA 2000 PROGRAM (2000).

[3] F.Van Der Heidjen, Image based measurement systems object recognition and parameter estimation, England - John Wiley \& Sons Inc, 1994.

[4] D. Plaut, S. Nowlan, G. E. Hinton, Experiments on learning by backpropagation, Computer Science Department Carnegie - Mellon University, Technical Report CMU-CS (1986) 86-126.

[5] H. K. D. H. Bhadeshia, Neural networks in materials science, ISIJ International 39 (1999) 966-979. 
[6] H. K. D. H. Bhadeshia, Neural networks and genetic algorithms in materials science and engineering, Tata McGraw-Hill Publishing Company Ltd., India, 2006.

[7] L. Miaoquan, X. Liu, A. Xiong, X. Li, Microstructural evolution and modelling of the hot compression of a TC6 titanium alloy, Materials Characterization 49 (2003) 203-209.

[8] L. Miaoquan, X. Liu, A. Xiong, X. Li, An adaptive prediction model of grain size for the forging of Ti-6Al-4V alloy based on the fuzzy neural networks, Journal of Materials Processing Technology 123 (2002) 377-381.

[9] I. Kim, Y. Jeong, C. Lee, P. Yarlagadda, Prediction of welding parameters for pipeline welding using an intelligent system, The International Journal of Advanced Manufacturing Technology 22 (2003).

[10] J. Kusiak, R. Kuziak, Modelling of microstructure and mechanical properties of steel using the artificial neural network, Journal of Materials Processing Technology 127 (2002) 115 - 121.

[11] X. Li, L. Miaoquan, Microstructure evolution model based on deformation mechanism of titanium alloy in hot forming, Transactions of non ferrous metals society of China 15 (2005) 749-753.

[12] R. Biernacki, J. Kozłowski, D. Myszka, M. Perzyk, Prediction of properties of austempered ductile iron assisted by artificial neural network, Materials Science (Medžiagotyra) 12 (2006) 11-15.

[13] A. Abdelhay, Application of artificial neural networks to predict the carbon content and the grain size for carbon steels, Egyptian Journal of Solids 25 (2002) 229 - 243.

[14] O. Wang, J. Lai, D. Sun, Artificial neural network models for predicting flow stress and microstructure evolution of a hydrogenized titanium alloy, Key Engineering Materials (2007) $541-544$.

[15] T. Chow, Neural networks and computing, World Scientific Pub, USA, 2007.

[16] S. Haykin, Neural networks: a comprehensive foundation, Macmillian College Publishing Company Inc, USA, 1994. 
[17] W. Callister, Materials science and engineering: an introduction, John Wiley \& Sons Inc, USA, 2006.

[18] V. Chiaverini, Tratamentos térmicos das ligas ferrosas, Associação Brasileira de Metais, 2a edição, São Paulo, Brazil, 1987.

[19] D. Raabe, F. Roters, F. Frédéric Barlat, L. Chen, Continuum scale simulation of engineering materials, Wiley InterScience Newsletter, 2005.

[20] W. Wang, Engineering alloys: properties and applications. Marcel Dekker Inc, USA, 2007.

[21] D. Zhang, T. C. Leia,, Z. Zhang,, J. Ouyang, The effects of heat treatment on microstructure and erosion properties of laser surface-clad Ni-base alloy, Surface and Coatings Technology 115 (1999) $176-183$.

[22] V. H. C. Albuquerque, P. C. Cortez, A. R. Alexandria, Image segmentation system for quantification of microstructures in metals using artificial neural networks, Revista Matéria 12 (2007) 394-407.

[23] A. Seabra, Correlação das propriedades mecânicas dos aços com a microestrutura. Lisboa Memória LNEC nº 522, 1979.

[24] V. H. C. Albuquerque, C. C. Silva, C.R.O. Moura, W. M. Aguiar, J.P. Farias, Effect of base metal characteristics on the success of welding of the AISI 4140 steel without post welding heat treatment, XXXIV National Welding Congress (2007). 


\section{FIGURES}

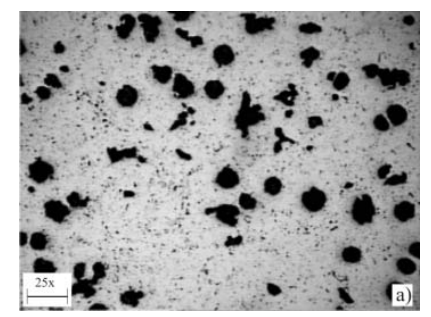

a)

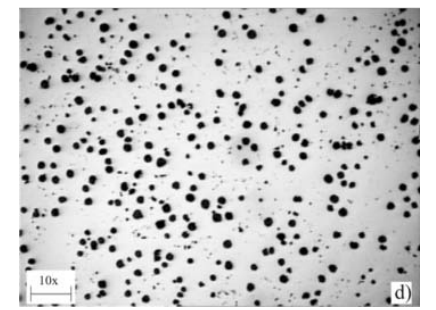

d)

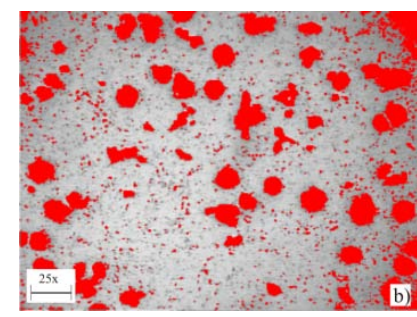

b)

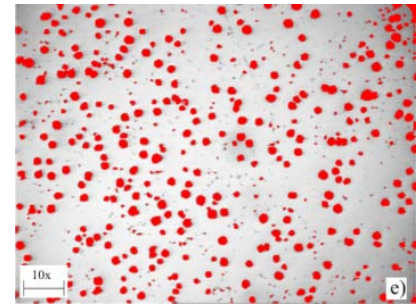

e)

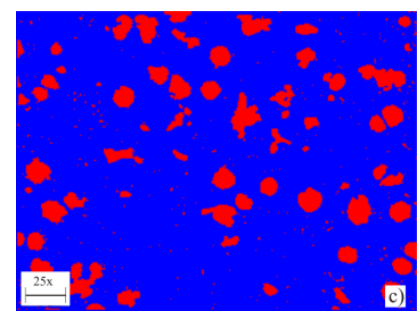

c)

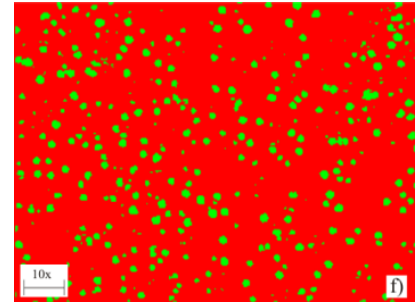

f)

Figure 1: Two original images of a nodular cast iron, a) and d); Resultant images of the segmentation done using a common commercial system, b) and e), and the corresponding images obtained using our system, c) and f).

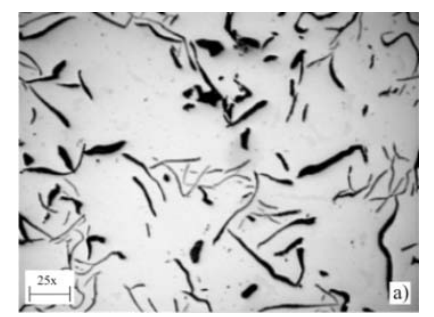

a)

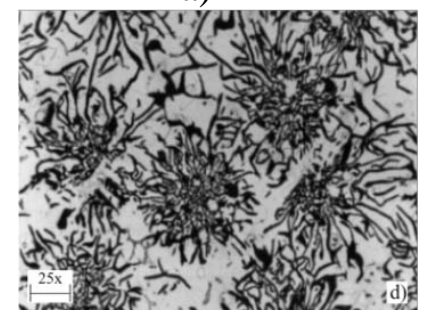

d)

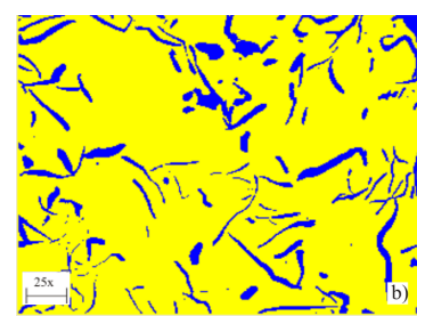

b)

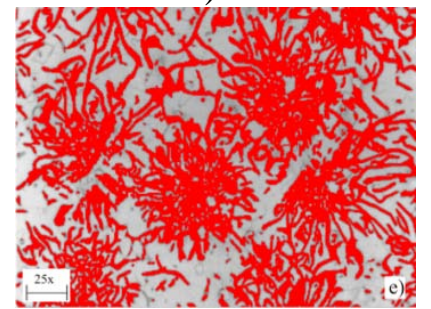

e)

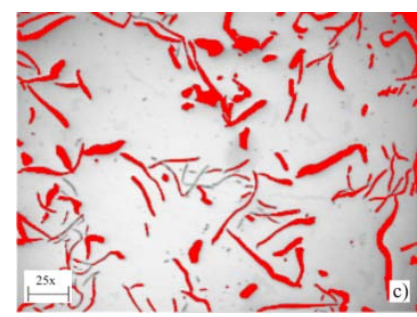

c)

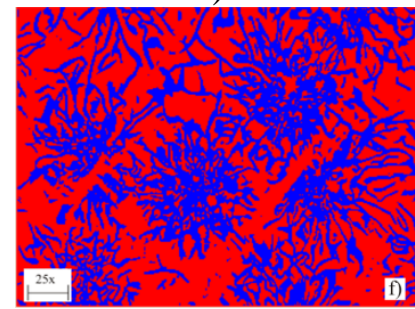

f)

Figure 2: Two original images of a gray cast iron, a) and d); Resultant images of the segmentation done using a common commercial system, b) and e), and the corresponding images obtained using our system, c) and f). 


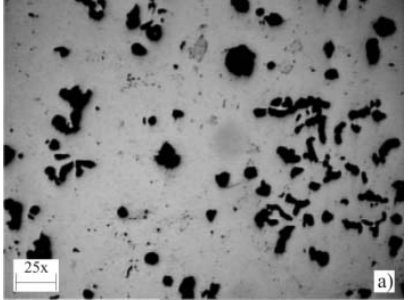

a)

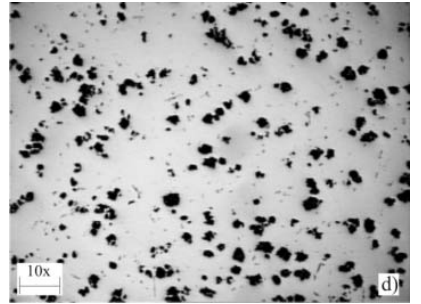

d)

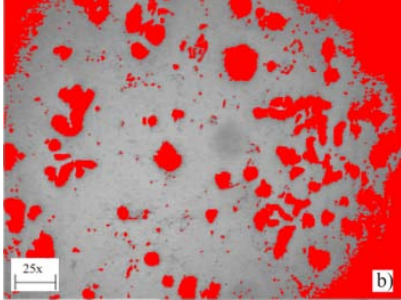

b)

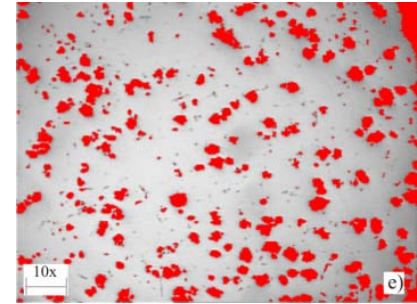

e)

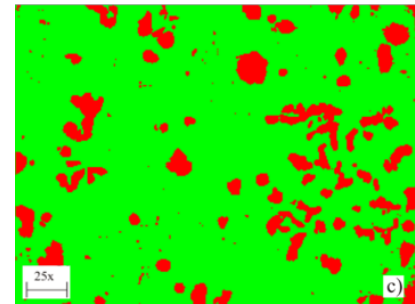

c)

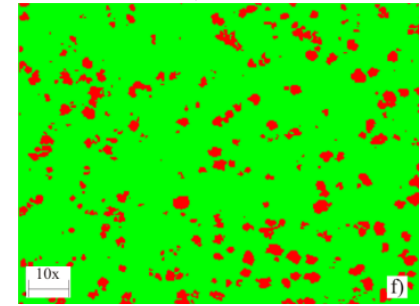

f)

Figure 3: Two original images of a malleable cast iron, a) and d); Resultant images of the segmentation done using a common commercial system, b) and e), and the corresponding images obtained using our system, c) and f).

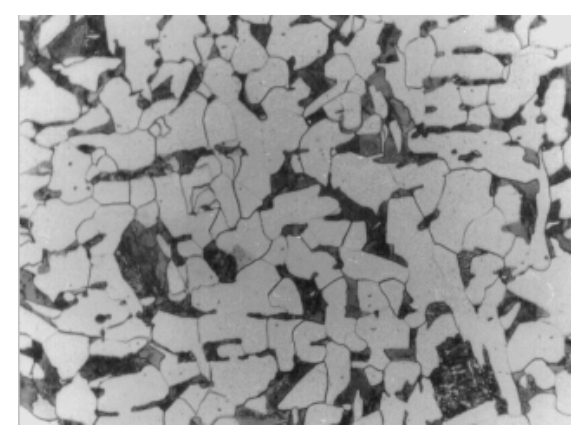

a)

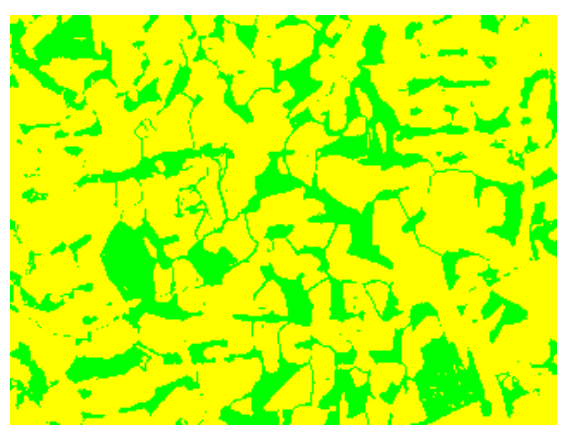

b)

Figure 4: An original image of an AISI 1020 steel, a), and the image resultant by segmentation using our system, b). 


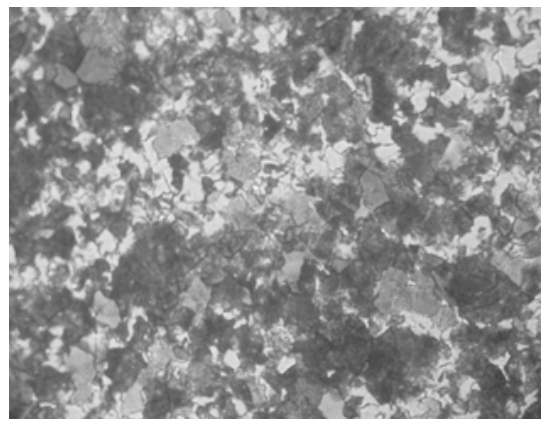

a)

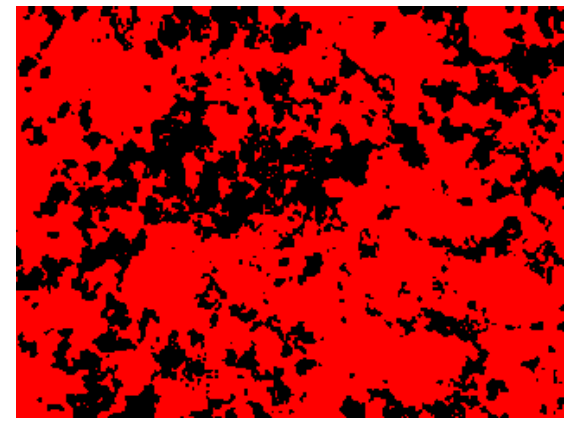

b)

Figure 5: An original image of an AISI 1045 steel, a), and the image resultant by segmentation using our system, b).

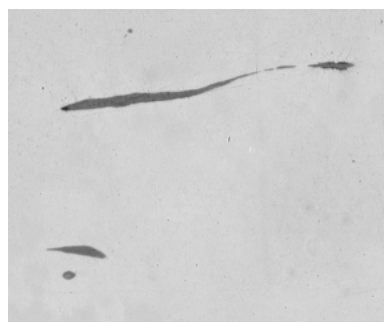

a)

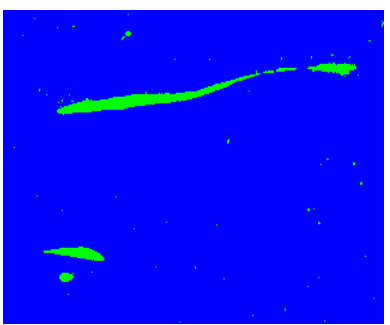

b)

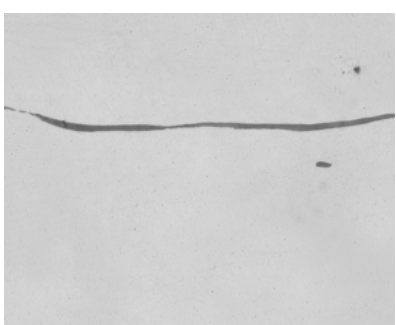

c)

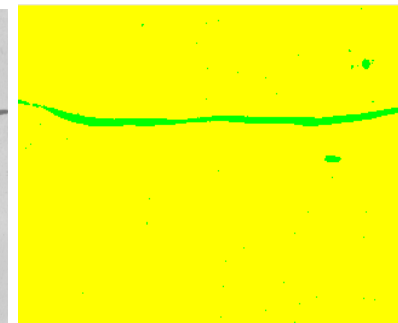

d)

Figure 6: Two original images of inclusions, a) and c), and the corresponding images segmented by our system, b) and d). 


\section{TABLES}

Table 1: Results obtained using the SVRNA and common commercial systems on samples of nodular cast iron.

\begin{tabular}{|l|c|c|c|c|}
\hline \multicolumn{5}{|c|}{ Nodular cast iron } \\
\hline \multirow{2}{*}{ Samples } & \multicolumn{2}{|c|}{ SVRNA } & \multicolumn{2}{c|}{ Commercial system } \\
\cline { 2 - 5 } & $\begin{array}{c}\text { Graphite } \\
(\%)\end{array}$ & $\begin{array}{c}\text { Pearlite } \\
(\%)\end{array}$ & $\begin{array}{c}\text { Graphite } \\
(\%)\end{array}$ & $\begin{array}{c}\text { Pearlite } \\
(\%)\end{array}$ \\
\hline Sample1 & 11.51 & 88.49 & 17.52 & 82.48 \\
\hline Sample 2 & 13.36 & 86.64 & 19.91 & 80.09 \\
\hline Sample 3 & 13.19 & 86.81 & 18.05 & 81.95 \\
\hline Sample 4 & 13.46 & 86.54 & 17.63 & 82.37 \\
\hline Sample 5 & 12.46 & 87.54 & 16.98 & 83.02 \\
\hline Sample 6 & 11.79 & 88.21 & 17.07 & 82.93 \\
\hline Sample 7 & 14.58 & 85.42 & 18.38 & 81.62 \\
\hline Sample 8 & 12.50 & 8.50 & 17.79 & 82.21 \\
\hline Sample 9 & 14.02 & 85.98 & 21.12 & 78.88 \\
\hline Sample 10 & 13.30 & 86.70 & 18.12 & 81.88 \\
\hline Sample 11 & 9.08 & 90.92 & 12.44 & 87.56 \\
\hline Sample12 & 9.25 & 90.75 & 11.85 & 88.15 \\
\hline Sample 13 & 11.56 & 88.44 & 14.35 & 85.65 \\
\hline Sample 14 & 9.24 & 90.76 & 11.39 & 88.61 \\
\hline Sample 15 & 10.22 & 89.78 & 12.82 & 87.18 \\
\hline Sample 16 & 9.89 & 90.11 & 12.74 & 87.26 \\
\hline Sample17 & 8.31 & 91.69 & 11.30 & 88.7 \\
\hline Sample 18 & 7.66 & 92.34 & 10.03 & 89.97 \\
\hline Sample 19 & 14.66 & 85.34 & 11.37 & 88.63 \\
\hline Sample 20 & 21.73 & 78.27 & 27.77 & 72.23 \\
\hline Average & 12.09 & 87.91 & 15.93 & 84.07 \\
\hline
\end{tabular}

Table 2: Average results obtained using the manual quantification method, SVRNA and common commercial systems, on samples of nodular cast iron.

\begin{tabular}{|l|c|c|}
\hline Method & Graphite (\%) & Pearlite/Ferrite (\%) \\
\hline Manual & 24.13 & 75.87 \\
\hline SVRNA & 12.09 & 87.91 \\
\hline $\begin{array}{l}\text { Commercial } \\
\text { system }\end{array}$ & 15.93 & 84.07 \\
\hline
\end{tabular}


Table 3: Results obtained using the SVRNA common commercial systems on samples of gray cast iron.

\begin{tabular}{|l|c|c|c|c|}
\hline \multicolumn{5}{|c|}{ Gray cast iron } \\
\hline \multirow{3}{*}{ Samples } & \multicolumn{2}{|c|}{ SVRNA } & \multicolumn{2}{c|}{ Commercial system } \\
\cline { 2 - 5 } & $\begin{array}{c}\text { Graphite } \\
(\%)\end{array}$ & $\begin{array}{c}\text { Pearlite } \\
(\%)\end{array}$ & $\begin{array}{c}\text { Graphite } \\
(\%)\end{array}$ & $\begin{array}{c}\text { Pearlite } \\
(\%)\end{array}$ \\
\hline Sample1 & 12.21 & 87.79 & 12.31 & 87.69 \\
\hline Sample2 & 6.80 & 93.20 & 7.20 & 92.80 \\
\hline Sample3 & 8.56 & 91.44 & 10.70 & 89.30 \\
\hline Sample4 & 6.80 & 93.20 & 8.36 & 91.64 \\
\hline Sample5 & 8.03 & 91.97 & 10.96 & 89.04 \\
\hline Sample6 & 5.02 & 94.98 & 6.91 & 93.09 \\
\hline Sample7 & 8.73 & 91.27 & 11.21 & 88.79 \\
\hline Sample8 & 9.15 & 90.85 & 11.00 & 89.00 \\
\hline Sample9 & 7.90 & 92.10 & 9.82 & 90.18 \\
\hline Sample10 & 6.67 & 93.33 & 8.35 & 91.65 \\
\hline Sample11 & 40.41 & 59.59 & 46.85 & 53.15 \\
\hline Sample12 & 7.47 & 92.53 & 10.66 & 89.34 \\
\hline Sample13 & 9.83 & 90.17 & 12.77 & 87.23 \\
\hline Sample14 & 7.52 & 92.48 & 10.52 & 89.48 \\
\hline Sample15 & 21.69 & 78.31 & 15.40 & 84.60 \\
\hline Sample16 & 8.79 & 91.21 & 9.70 & 90.30 \\
\hline Sample 17 & 7.76 & 92.24 & 10.21 & 89.79 \\
\hline Sample18 & 6.77 & 93.23 & 9.28 & 90.72 \\
\hline Sample19 & 7.64 & 90.28 & 8.21 & 91.79 \\
\hline Sample 20 & 7.78 & 92.22 & 11.35 & 88.65 \\
\hline Average & 10.28 & 89.62 & 12.09 & 87.91 \\
\hline
\end{tabular}


Table 4: Results obtained using the SVRNA and common commercial systems on samples of malleable cast iron.

\begin{tabular}{|l|c|c|c|c|}
\hline \multicolumn{5}{|c|}{ Malleable cast iron } \\
\hline \multirow{2}{*}{ Samples } & \multicolumn{2}{|c|}{ SVRNA } & \multicolumn{2}{c|}{ Commercial system } \\
\cline { 2 - 5 } & $\begin{array}{c}\text { Graphite } \\
(\%)\end{array}$ & $\begin{array}{c}\text { Pearlite } \\
(\%)\end{array}$ & $\begin{array}{c}\text { Graphite } \\
(\%)\end{array}$ & $\begin{array}{c}\text { Pearlite } \\
(\%)\end{array}$ \\
\hline Sample 1 & 18.95 & 81.05 & 31.65 & 68.35 \\
\hline Sample 2 & 15.71 & 84.29 & 24.48 & 75.52 \\
\hline Sample 3 & 14.96 & 85.04 & 28.46 & 71.54 \\
\hline Sample 4 & 14.00 & 86.00 & 29.16 & 70.84 \\
\hline Sample 5 & 15.16 & 84.84 & 24.08 & 75.92 \\
\hline Sample 6 & 16.07 & 83.93 & 21.11 & 78.89 \\
\hline Sample 7 & 19.11 & 80.89 & 30.55 & 69.45 \\
\hline Sample 8 & 19.22 & 80.78 & 27.58 & 72.42 \\
\hline Sample 9 & 15.64 & 84.36 & 23.89 & 76.11 \\
\hline Sample 10 & 17.64 & 82.36 & 31.23 & 68.77 \\
\hline Sample 11 & 11.84 & 88.16 & 18.23 & 81.77 \\
\hline Sample 12 & 12.04 & 87.96 & 21.12 & 78.88 \\
\hline Sample 13 & 13.72 & 86.28 & 22.62 & 77.38 \\
\hline Sample 14 & 14.06 & 85.94 & 22.24 & 77.76 \\
\hline Sample 15 & 11.83 & 88.17 & 17.15 & 82.85 \\
\hline Sample 16 & 11.40 & 88.60 & 16.16 & 83.84 \\
\hline Sample 17 & 11.30 & 88.70 & 17.83 & 82.17 \\
\hline Sample 18 & 10.68 & 89.32 & 14.23 & 85.77 \\
\hline Sample 19 & 21.05 & 78.95 & 14.39 & 85.61 \\
\hline Sample 20 & 15.27 & 84.73 & 21.63 & 78.37 \\
\hline Average & 14.98 & 85.02 & 22.89 & 77.11 \\
\hline
\end{tabular}

